\title{
Análise da temperatura do ar, precipitação, evapotranspiração e índice hídrico do município de Itapetinga-BA
}

\author{
Air temperature analysis, precipitation, evapotranspiration and water content of \\ the municipality of Itapetinga - BA \\ CARVALHO $^{1}$, T. O.; CONCEIÇÃO ${ }^{1}$, R. S.; SILVA, ${ }^{1}$ J. A. S. S.; VEIGA², A. J. P. \\ tatianeocb@outlook.com
}

\section{Resumo}

Para a realização desse estudo foram considerados alguns elementos do clima, como temperatura, precipitação, evapotranspiração e índice hídrico do município de Itapetinga - BA, no período de 1961 a 1990. O objetivo foi de analisar as variações climáticas do município com uma perspectiva de compreender o comportamento do clima local e seus possíveis efeitos na região e, também, fornecer subsídios para planejamento regional. Foram utilizados dados meteorológicos do Instituto Nacional de Meteorologia (INMET), com um recorte temporal dos anos de 1961 a 1990. Com os resultados obtidos conclui-se que, o município que possui um clima que varia de semiárido a úmido, apresenta temperaturas que oscilaram entre $19,9^{\circ} \mathrm{C}$ e $25,3^{\circ} \mathrm{C}$. O índice de evapotranspiração foi superior à precipitação, com exceção do mês de novembro. O município apresenta déficit hídrico com grande variabilidade, principalmente dos meses de julho para setembro. Devido as características climáticas do município de Itapetinga torna-se necessário medidas mitigadoras que levem em consideração os aspectos do clima local e, também, no que tange a planejamentos ambientais, disponibilidade hídrica, produção agrícola e, principalmente, nas tomadas de decisões.

Palavras chaves: Balanço Hídrico. Clima regional. Elementos do clima.

\begin{abstract}
For this study were considered some climate elements as temperature, precipitation, evapotranspiration and water content of the municipality of Itapetinga - BA, from 1961 to 1990 . The aim was to analyse the climatic variations of the municipality with a perspective of to understand the local climate behavior and their possible effects in the region and also provide grants for regional planning. Were used meteorological data of the National Institute of Meteorology (INMET), with a time frame from 1961 to 1990 . With the results it is concluded that the municipality has a climate that varies from semi-arid to humid, with temperatures that ranged between $19,9{ }^{\circ} \mathrm{C}$ and $25,3{ }^{\circ} \mathrm{C}$. The evapotranspiration rate was higher than the rainfall, except for the month of November. The city has water deficit with great variability, especially the months of July to September. Due to the climatic characteristics of the Itapetinga city it becomes necessary mitigation measures that take into account aspects of the local climate and also with respect to environmental planning, water availability, agricultural production, and especially in decision-making.
\end{abstract}

Key words: climate elements. Hydric balance. regional climate.

\footnotetext{
${ }^{I}$ Tatiane de Oliveira Carvalho, Renaildo Santos da Conceição, Jonathan Aurélio Sousa Sales Silva, graduandos em Geografia pela Universidade Estadual do Sudoeste da Bahia, Vitória da Conquista - BA, Brasil.

${ }^{2}$ Artur José Pires Veiga, Professor Titular do Departamento de Geografia da Universidade Estadual do Sudoeste da Bahia, Vitória da Conquista - BA, Brasil.
} 


\section{INTRODUÇÃO}

O clima é um dos principais agentes para a vida no Planeta Terra, tem grande atuação na estrutura geológica, no relevo, solo, vegetação, faunas, rios, entre outros. Dada a sua importância, a análise climática tem contribuído significativamente para a compreensão das dinâmicas espaciais, auxiliando na busca e no entendimento do funcionamento do sistema como um todo, em uma perspectiva voltada, sobretudo, para o planejamento do território rural e urbano.

A climatologia, mesmo antes de um conhecimento cientifico sistematizado, já era utilizada por diversos povos, segundo Sant' Anna Neto (2004) existe pouca literatura sobre o conhecimento que os povos indígenas, que habitavam o Brasil no início da ocupação portuguesa, tinham a respeito dos fenômenos atmosféricos. Esclarece ainda que muitos destes povos se preocupavam com o tempo e o clima, na medida de sua importância, não somente mística, como também no que se relaciona às suas atividades agrícolas, de caça e comemorativas. Assim, verifica-se ainda que a relação da dinâmica do tempo e do clima está presente na sociedade desde tempos remotos, contribuindo para a organização e planejamento dos povos.

No contexto da sociedade atual, é de suma importância o conhecimento da variabilidade climática em suas diversas escalas: nacional, regional e local, para planejamentos territoriais que visem a dinâmica dos climas. Nesta perspectiva Monteiro (1991, p. 19) elucida que:

A nível regional, à medida que se percebem as correlações complexas
e uma concepção mais comportamental e complexa do clima é que
nos damos conta de que como os estados de tempo oscilam, admitem
desvios e produzem "acidentes" que não podem ser considerados
excepcionais. Mesmo os mais graves, por vezes catastróficos, se
estatisticamente poderiam ser tomados como "ruído", seu impacto
local ou regional e a reação em cadeia que lhes segue, fazem com que
eles não possam ser descartados.

Nos estudos sobre o clima do Nordeste Zavattini (2004), assegura que pode-se fazer afirmações geograficamente óbvias, como por exemplo, a de que se trata de uma terra de contrastes. Afirma também que muitos estudos ainda precisam ser realizados para esta região, uma vez que apresenta contrates rítmicos entre a zona da mata, o agreste e o sertão. 
Salienta-se que, ao estudar os elementos climáticos de determinada região, é possível compreender como estes podem interferir e contribuir com a dinâmica e organização do espaço local, como ilustram Conceição; Pereira e Veiga (2016, p. 73),

A organização do espaço é uma das tarefas mais importantes para o geógrafo, no campo da Climatologia o profissional se incumbirá de estudar os elementos e fatores do clima para assim entender a relação que cada um deles exerce sobre as paisagens, relevo e a população do local estudado. Ademais, o clima exerce uma dinâmica e variabilidade em cada região de forma particular.

Nos estudos sobre o comportamento de um microclima, é necessário um prévio conhecimento sobre alguns dos elementos e fatores climáticos do local em análise. Sobre a temperatura do ar Ayoade (2001), assegura que é determinada pela entrada e saída de radiação que um corpo possui e ainda pela sua transformação em calor latente e sensível, ainda que, a temperatura do ar varia de lugar e com o decorrer do tempo em uma determinada localidade. A latitude, o relevo, os ventos, as correntes oceânicas são fatores que interferem na dinâmica espacial da temperatura.

A precipitação em forma de chuva, como salienta Ross (2011), pode variar de região para região, e os totais de chuva podem ser semelhantes entre elas, porém, com uma distribuição diferente ao longo do ano. Garcez e Alvarez (1988) conceituam as precipitações atmosféricas como um conjunto de águas originadas do vapor de água atmosférico que cai, em estado líquido ou sólido, sobre a superfície da terra. Ainda ratificam que, o conceito engloba, não somente a chuva, mas também a neve, o granizo, o nevoeiro, o sereno e a geada. Entretanto, é somente a chuva e a neve que contribuem expressivamente com os índices de precipitação. Para Marcuzzo e Goularte (2012) um dos fenômenos físicos decorrentes da variabilidade climática é a variabilidade da precipitação pluvial, e que também é um importante controlador do ciclo hidrológico e uma das variáveis climáticas que possui maior influência na transformação da paisagem e do meio ambiente.

A evapotranspiração como outro elemento importante é, resultado da combinação da evaporação e transpiração, que transformam a água da superfície da Terra em vapor. Uma temperatura alta, influi na intensidade de evaporação, por meio da saturação do ar. Nesta perspectiva, Ayoade (2001, p. 129) salienta que:

A taxa de evaporação ou de evapotranspiração em uma dada área é determinada por dois principais fatores. Um é a disponibilidade de umidade na superfície onde há evaporação, enquanto o outro é a capacidade da atmosfera de vaporizar a água, remover e transportar o 
vapor para cima. Se houver sempre umidade disponível na superfície onde ocorre a evaporação (isto é, superfície não limitante), então a evaporação e a evapotranspiração ocorrerão na razão máxima possível para aquele ambiente.

A distribuição da água na superfície terrestre influencia no clima das regiões, nesta perspectiva Conti e Furlan (2011), salientam que, o ritmo das chuvas pode ser sazonal, e que nos trópicos muitos organismos têm seu ciclo de vida condicionados pelos ciclos de pluviosidade. Para as plantas, o balanço entre as precipitações e a evapotranspiração é que vai determinar o tipo de comunidade biológica de uma região, sendo que, a umidade é especialmente importante para a regulação da temperatura.

A classificação do clima, não está restrita a elementos avulsos, mas sim, da relação de diversos fatores entre si. Em seus estudos Ross (2011), destaca que o clima, não deve ser caracterizado apenas pela temperatura do ar, mas pelo conjunto de seus elementos, ou seja, precipitação, ventos, umidade relativa, evaporação, entre outros elementos e fatores do clima, todos em permanente dinamismo

Dessa forma, o objetivo desse estudo foi de analisar os elementos do clima, como a temperatura do ar, precipitação, evapotranspiração e índice hídrico do município de Itapetinga-BA. Para esse estudo foi feito um recorte temporal dos anos de 1961 a 1990, com uma perspectiva de compreender o comportamento do clima local e seus possíveis efeitos na região.

A relevância desse estudo está em compreender as variações climáticas do município de Itapetinga em relação a sua dinâmica climática, haja vista que os resultados poderão oferecer subsídios no que tange ao planejamento ambiental e os possíveis indicativos de alerta para a população local.

O município de Itapetinga (figura 1) está localizado no Estado da Bahia e pertence a mesorregião do Centro-Sul Baiano, uma área com unidade territorial de $1.627,462 \mathrm{~km}^{2}$, possui uma população de 68.273 habitantes, e um bioma de Mata Atlântica (IBGE, 2010). O relevo pertencente a unidade geomorfológica Depressão Itabuna-Itapetinga, com altimetria variando entre 255 a $400 \mathrm{~m}$ de altitude. A área possui uma tipologia climática que varia de semiárido a úmido.

O município de Itapetinga se configurou territorialmente como o desenvolvimento da atividade agropastoril, como principal atividade econômica, e em menor escala, os setores de serviços, comércio e educação, tendo uma função de polo na microrregião. As oscilações climáticas influenciam diretamente na atividade agropastoril, com reflexo na economia local/regional. 
A vegetação nativa da região praticamente foi substituída pela pastagem, permanecendo alguns remanescentes florestais nas propriedades, inclusive uma Área de Preservação Ambiental em área rural.

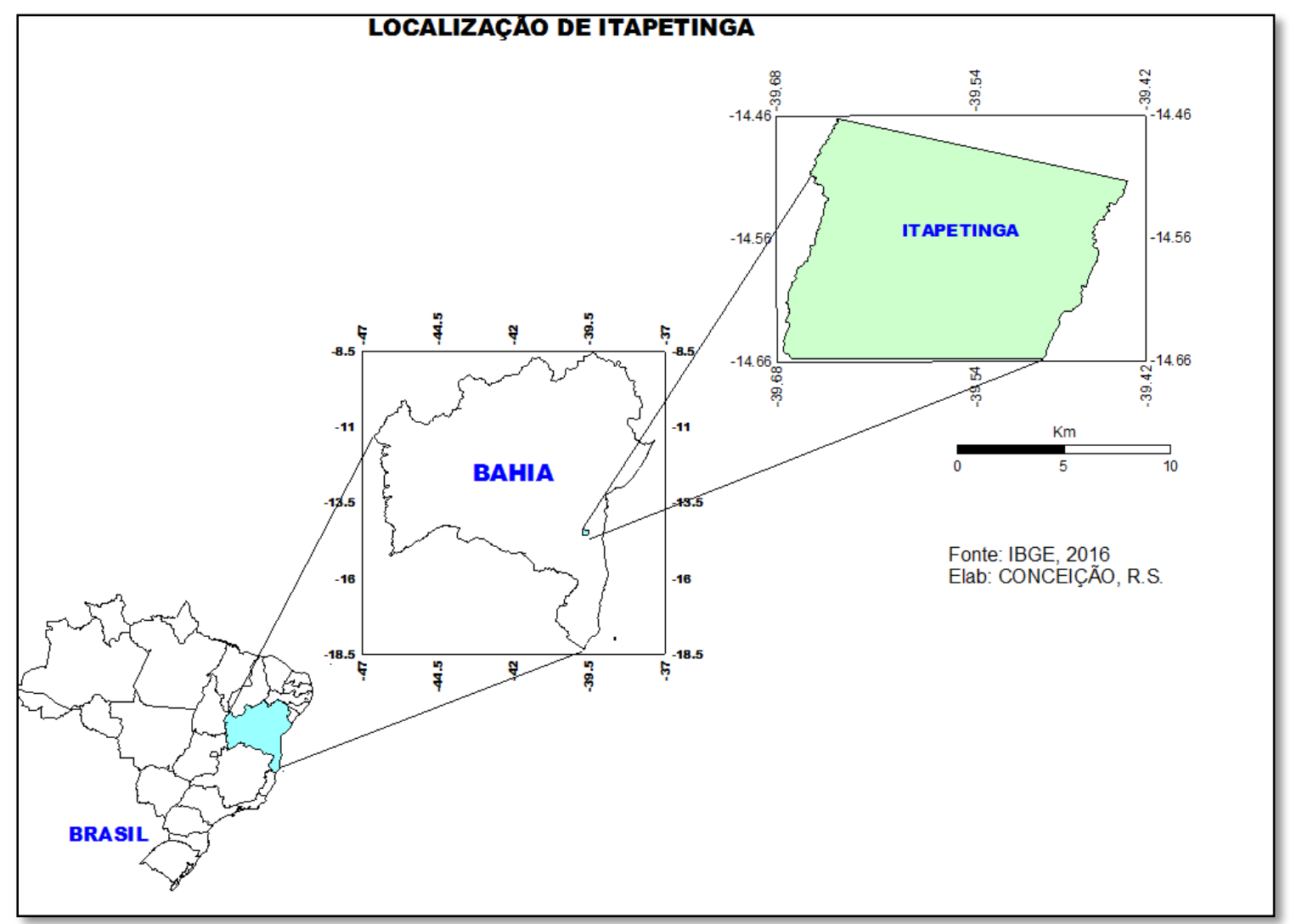

Figura 1. Itapetinga-B A, localização do município, 2016.

Fonte: Base cartográfica do IBGE, 2016. Elaborado pelos autores, 2016.

No que diz respeito aos recursos hídricos, a região pertence a bacia do Rio Pardo em confluência com a sub-bacia do rio Catolé, composta dos rios: Catolé Grande, Riacho Sapucaia, Riacho Duas Barras, Rio Colônia, Riacho das Palmeiras, Córrego de Serrinha, Rio Catolezinho e Rio da Onça.

\section{METODOLOGIA}

Para a realização deste estudo, foi realizado um levantamento de dados meteorológicos visando-se a análise das variações da temperatura do ar, precipitação, evapotranspiração e índice hídrico mensal e anual do município de Itapetinga-BA. Para 
tal procedimento utilizou-se um recorte temporal do período de 1961 a 1990, somando 30 anos de dados com o intuito de compreender as características e oscilações climáticas do local.

Para isso, foram necessários dados meteorológicos do município de Itapetinga, cujos dados foram coletados no Instituto Nacional de Meteorologia (INMET), disponíveis na Superintendência de Estudos Econômicos e Sociais do Estado da Bahia (SEI).

Para tabulação e compilação destes dados, empregou-se o software Excel para transformação das médias mensais em mensais/anuais. Teve como estratégia trabalhar com as médias mensais/anuais para facilitar a compreensão dos resultados, uma vez que, seria grande a quantidade de dados se trabalhasse apenas com médias mensais e poderia dificultar a compreensão dos resultados.

Ainda, para melhores esclarecimentos dos resultados, necessitou-se de geração de gráficos para as possíveis elucidações sobre a variabilidade de cada elemento e fator do clima de Itapetinga, tendo como base a classificação climática de Thomthwaite.

Com o intuito de resultados mais coesos e abrangentes, correlacionou alguns dos elementos do clima, como precipitação e evapotranspiração. Ainda, para a elaboração do mapa de localização do município em análise, utilizou-se o software MapViewer 7.2 e as bases cartográficas vetoriais no formato shapefille, disponíveis no IBGE.

\section{RESULTADOS E DISCUSSÃO}

O município se caracteriza por clima que varia de semiárido a úmido, com pouca variação na amplitude térmica. Na análise do climograma de Itapetinga - BA (figura 2), percebe-se que os meses com temperaturas mais elevadas, janeiro, fevereiro e março, a precipitação oscila entre 70,3 a 92,6 mm que são as maiores em relação a meses anteriores a novembro. Do mês de maio a setembro, as temperaturas médias não ultrapassam $23^{\circ} \mathrm{C}$ e são os meses com as precipitações mais baixas do ano, registrando 25,9 mm no mês de setembro. A partir de outubro, a temperatura começa a se elevar novamente, mas sem ultrapassar as do início do ano. Os meses de novembro e dezembro são os que registram as maiores precipitações, $134,1 \mathrm{~mm}$ em novembro e $115,6 \mathrm{~mm}$ em dezembro, com temperaturas médias que variam entre 23,8 e $24,3{ }^{\circ} \mathrm{C}$. 


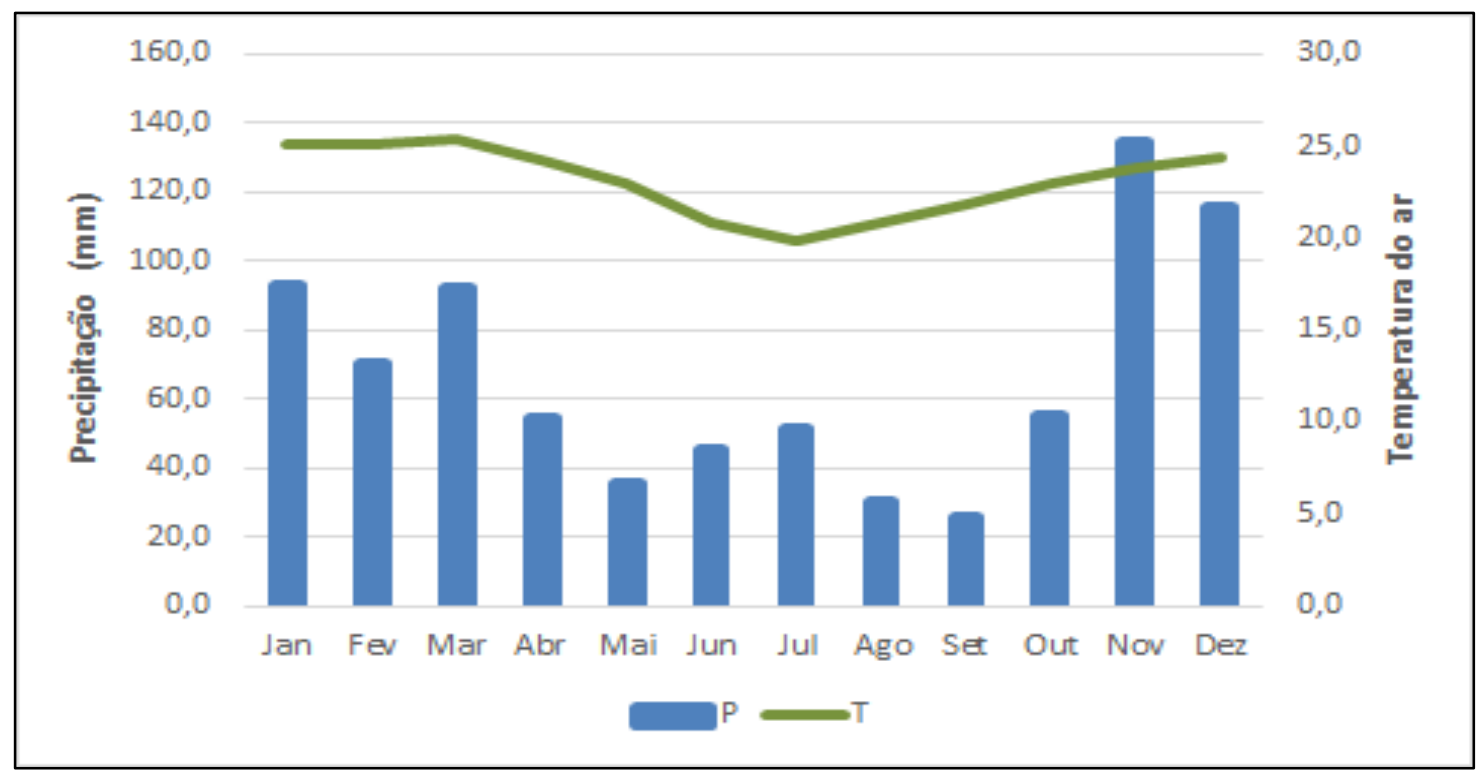

Figura 2. Itapetinga-Ba, relação das precipitações com as médias mensais anuais da temperatura do ar no período de 1961 a 1990

Fonte: INMET (1991), SEI (1999). Elaborado pelos autores, 2016.

$\mathrm{Na}$ análise das precipitações observa-se que, a média das totais anuais foi de 803,3 mm, enquanto que a evapotranspiração foi de 1151,4 mm, no período de 1961 a 1990 . Ao analisar esses dois elementos por mês/ano no mesmo período (figura 3), foi observado que, somente no mês de novembro a precipitação que chegou a $134,1 \mathrm{~mm}$, foi superior a evapotranspiração registrada no mesmo período com 106,9 mm. Nos demais meses, o índice de evapotranspiração foi superior à precipitação. Os volumes pluviométricos mais baixos aconteceram nos meses de maio a setembro, com índices entre 25,9 a 51,5 mm, caracterizado pelos meses onde a temperatura do ar atinge os níveis mais baixos.

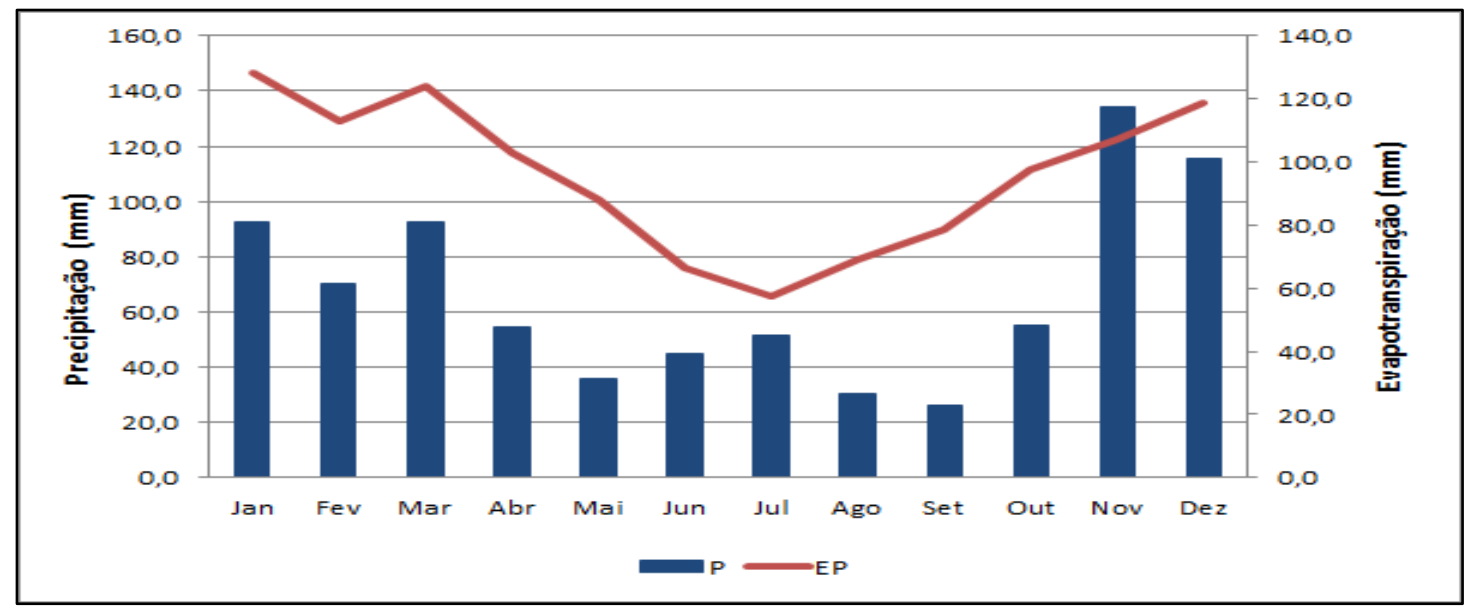

Figura 3. Itapetinga-Ba, relação das médias mensais anuais de precipitação e evapotranspiração no período de 1961 a 1990

Fonte: INMET (1991), SEI (1999). Elaborado pelo autor, 2016. 
Quanto ao déficit hídrico, o município apresenta com significativa variabilidade, conforme constatado na figura 4. Os meses de janeiro a maio e de agosto a outubro, apresentaram níveis negativos superiores a $-20,0 \mathrm{~mm} / \mathrm{mês}$, alcançando valores acima de $-50 \mathrm{~mm} / \mathrm{mês}$, com diminuição no déficit nos meses de junho e julho, com dados inferiores a $-20 \mathrm{~mm} / \mathrm{mês}$. Os meses de novembro e dezembro, apresentam os menores índices, 0,0 e $-1,5 \mathrm{~mm}$ respectivamente no período analisado.

Com os dados, percebe-se que, em relação à temperatura do ar tem-se uma pequena amplitude térmica, embora nos meses com temperaturas mais elevadas, são aqueles em que ocorrem os maiores índices pluviométricos. Quanto a evapotranspiração, em praticamente todo o ano a ocorrência foi superior a pluviometria, com exceção do mês de novembro, onde, o índice pluviométrico foi superior ao da evapotranspiração.

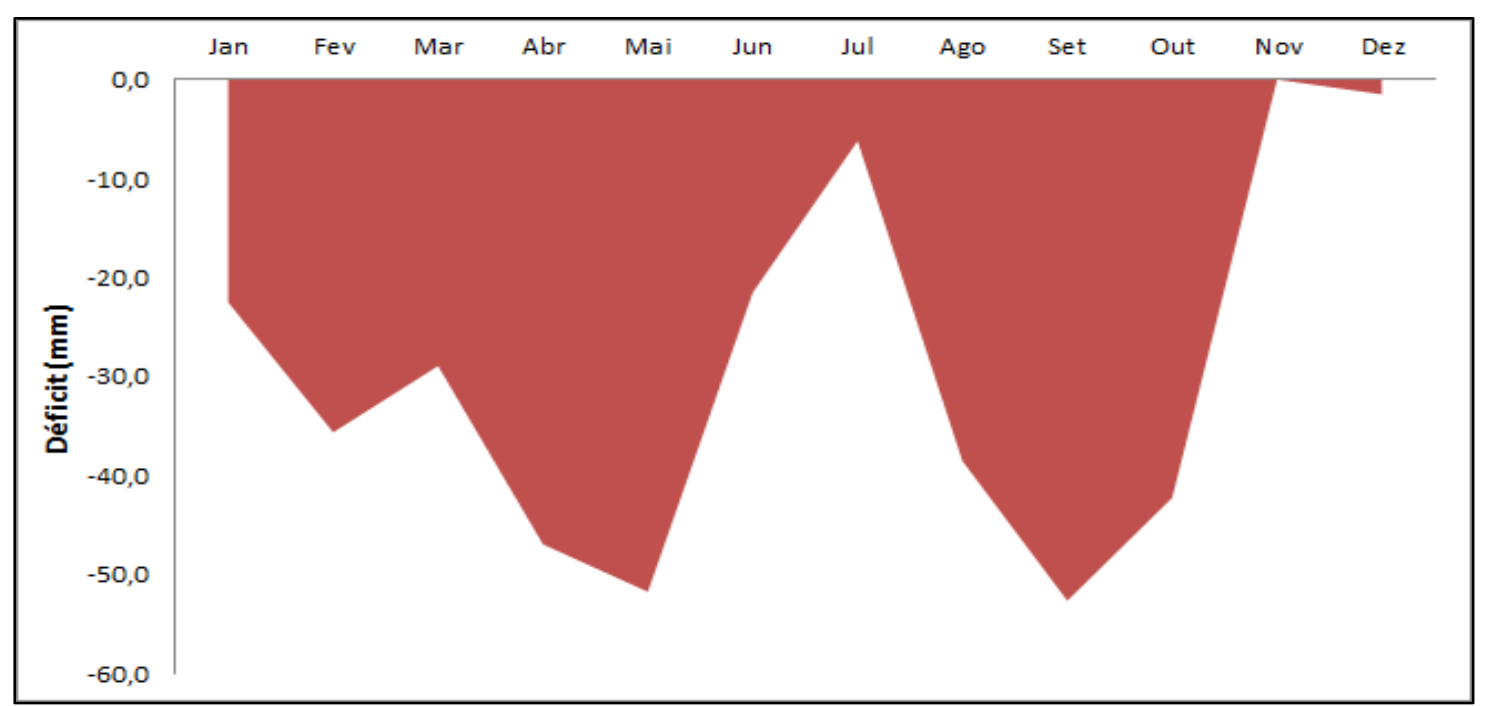

Figura 4. Itapetinga-Ba, Déficit hídrico mensal anual no período de 1961 a 1990

Fonte: INMET (1991), SEI (1999). Elaborado pelos autores, 2016.

O município de Itapetinga devido a características de uma região agropastoril, com um rebanho bovino significativo, as características climáticas influenciam diretamente na economia e na produção regional. As condições climáticas indicam índices que não são tão favoráveis para o desenvolvimento da pecuária na região, com baixa disponibilidade pluviométrica e de excedente, conforme indicado no balanço hídrico, cabendo aos produtores adequarem a sua atividade as variações climáticas que tem ocorrido na região. 


\section{CONSIDERAÇÕES FINAIS}

No município de Itapetinga com um clima que varia de semiárido a úmido, foi constatado que a temperaturas do ar apresentou baixa amplitude térmica. Os meses mais quentes é de janeiro à março, com máxima de $25,3{ }^{\circ} \mathrm{C}$.

Quanto a média de precipitação anual que foi de $803,3 \mathrm{~mm}$, apresentou uma distribuição irregular ao longo do ano. Somente no mês de novembro a precipitação média mensal foi maior que a evapotranspiração. Os índices pluviométricos que se apresentam mais baixos acontecem nos meses de maio a setembro, onde a temperatura do ar atinge as temperaturas mais baixas.

Assim, pode-se inferir que, o município de Itapetinga possui características climáticas importantes para o desenvolvimento da atividade agropastoril, no entanto a análise dos elementos do clima da região indicou variabilidades nesses elementos e que merecem certa atenção para o planejamento local/regional.

O clima da região por se apresentar com alta variabilidade, com uma evapotranspiração superior a precipitação e, consequentemente, elevado déficit hídrico, torna-se necessário medidas mitigadoras que levem em consideração estes aspectos do clima local e, também, no que tange a planejamentos ambientais, disponibilidade hídrica, produção agrícola e, principalmente, nas tomadas de decisões.

\section{REFERÊNCIAS}

AYOADE, J. O. Introdução a climatologia para os trópicos. 6. ed. - Rio de Janeiro: Bertrand Brasil, 2001.

BRASIL. Instituto Brasileiro de Geografia e Estatística. Disponível em: http://www.ibge.gov.br/home/. Acesso em: 10/07/2016.

CONCEIÇÃO, R. S.; PERAIRA, L. B.; VEIGA, A. J. P. Análise da temperatura do ar, precipitação, evapotranspiração, déficit e excedente hídrico em Vitória da Conquista - BA, de 1961 a 1990. Revista Eletrônica Geoaraguaia. Barra do Garças-MT. V 5, n.2, p. 71-83, 2016. Disponível em: http://revistas.cua.ufmt.br/geoaraguaia/index.php/geo. Acesso em: 10/08/2016. CONTI, José Bueno; FURLAN, Sueli Angelo. Geoecologia o clima, os solos e a biota. In: ROSS, Jurandir Luciano Sanches (org.). Geografia do Brasil. 6. ed. São Paulo: Editora da Universidade de São Paulo, 2011. 
GARCEZ, Lucas Nogueira, ALVAREZ, Guillermo Acosta. Hidrologia. 2. ed. São Paulo: Edgar Blücher, 1988.

INMET. Instituto Nacional de Meteorologia. Disponível em: http://www.inmet.gov.br. Acesso em: 10/07/2015.

MARCUZZO, F. F. N.; GOULARTE, E. R. P. Índice de Anomalia de Chuvas do Estado do Tocantins. Geoambiente On-line, v. 19, p. 55-71, 2012. Disponível em: www.revistas.ufg.br/geoambiente. Acesso em: 03/08/2016.

MONTEIRO, C. A de F. Clima e Excepcionalismo: Conjecturas sobre o Desempenho da Atmosfera como Fenômeno Geográfico. Florianópolis, Ed. Da UFSC, 1991.

ROSS, Jurandyr L. Sanches. Geografia do Brasil. 6. ed. São Paulo: Editora da Universidade de São Paulo, 2011.

SANT'ANNA NETO, J. L. História da Climatologia no Brasil: Gênese e paradigmas do clima como fenômeno geográfico. Florianópolis, Número 7, 2004.

SEI. Superintendência de Estudos Econômicos e Sociais da Bahia. Balanço hídrico do estado da Bahia. Salvador: SEI, 1999.

ZAVATTINI, J. A. Estudos do clima no Brasil. Campinas: Alínea, 2004.

Recebido em: 14/08/2016

Aceito para publicação em: 01/10/2016 